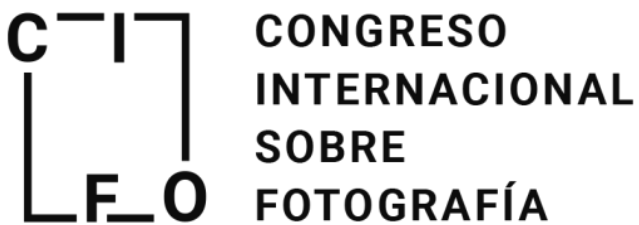

Congreso Internacional sobre Fotografía

UPV, 5 y 6 octubre 2017

Doi: http://dx.doi.org/10.4995/CIFo17.2017.6772

ISBN: 978-84-9048-604-7

\section{Exvotos fotográficos: la imagen usada como objeto de culto en la región de Alentejo}

\section{Milene Russo Trindade}

Universidade de Évora, CHAIA - Centro de história da arte e investigação artística, Laboratório HERCULES- Herança cultural, estudos e salvaguarda. Proyecto apoyado por la FCT - Fundação para a Ciência e Tecnologia. milene.trindade@gmail.com

\begin{abstract}
This article presents a PhD research about photographic votive offerings integrated in the Alentejo region of Portugal. It intends to point out the existence of these objects in the south of the country, which is also a reality in Spain. In the region of Alentejo, it is possible to find collections of hundreds of photographic portraits displayed on the walls of the churches, which raises the question of preservation. The text is based on case studies from the north of Alentejo such as the Santuário de Nossa Senhora d'Aires in Viana do Alentejo, the Ermida da Nossa Senhora da Visitação in Montemor-o-Novo or the Igreja do Senhor Jesus da Piedade in Elvas. The ultimate goal of this article is to provide information that helps understand photography as a votive offering, but above all, help propose a strategy towards the valorisation and heritage safeguarding of these objects.
\end{abstract}

Keywords: exvoto, votive offering, photography, preventive conservation, safeguard, religious heritage 


\begin{abstract}
Resumen
El siguiente texto expone una investigación doctoral sobre los exvotos fotográficos en la región de Alentejo en Portugal. Se pretende dar a conocer la existencia de estos objetos en el sur del país, siendo una realidad que también se encuentra en España. En la región de Alentejo, es posible encontrar colecciones constituidas por centenares de retratos fotográficos colgados en las paredes de las iglesias, lo que pone en tela de juicio la cuestión de su preservación. El texto se basa en casos de estudio de santuarios o ermitas localizadas en el Alto Alentejo como el Santuário de Nossa Senhora d'Aires en Viana do Alentejo, la Ermida da Nossa Senhora da Visitação en Montemor-o-Novo o la Igreja do Senhor Jesus da Piedade en Elvas. El objetivo de esta comunicación es aportar información que facilite la comprensión de la fotografía como oferta votiva, pero sobre todo, ayude a plantear una estrategia hacia la valorización y salvaguarda patrimonial de estos objetos.
\end{abstract}

Palabras clave: exvoto, fotografía, conservación preventiva, salvaguarda, patrimonio religioso

\title{
Introducción
}

El siglo XIX ha sido escenario de la introducción de la fotografía en las sociedades y de los constantes cambios que esta ha tenido a nivel tecnológico. De manera gradual la fotografía se incorporó a nuestro cotidiano, pasando la idea de tener y ofrecer fotografías a formar parte del imaginario común. Del mismo modo que las imágenes eran usadas como recuerdo dentro de un álbum de familia, se empezaron a usar también como ofrenda en el campo religioso.

En la presente comunicación, se expone la investigación doctoral sobre los exvotos fotográficos en la región de Alentejo, en Portugal. Los exvotos son ofertas que simbolizan el agradecimiento por una dádiva concedida, siendo común que previamente se haya rezado a un santo o santa pidiendo un voto. No se sabe con exactitud cuando empezó este ritual, pero sabemos que civilizaciones como la romana ya lo practicaban. Son ejemplo de ello los exvotos escultóricos encontrados en el templo galo-romano del bosque de Halatte ${ }^{1}$ en Francia o el deposito votivo de Garvão en el sur de Portugal, dónde se han encontrado

\footnotetext{
${ }^{1}$ Las esculturas votivas, encontradas en el templo galo-romano del bosque de Halatte en Francia, han sido concebidas en piedra calcaría y realizadas entre siglo I d.C. hasta el siglo V d.C..
} 
representaciones de ojos en chapa de oro y plata repujada, descritas por el arqueólogo Caetano M. Beirão como placas oculares (siglo IV a III a.C. $)^{2}$.

La oferta votiva es sobretodo conocida a través de formatos como el escultórico o el pictórico, sin embargo, como la fotografía pasó a ser un medio usado a gran escala con el viraje del siglo XIX al XX, terminó substituyendo progresivamente a la pintura. Si por un lado, la pintura recreaba una escena, por otro lado, tenemos las fotografías que se presentan como retratos individuales o de grupo. La riqueza formal y técnica de las colecciones de exvotos fotográficos, nos propone una lectura de la historia de sus técnicas, así como también, del modo en que ha evolucionado la presentación de fotografías. Observar estas colecciones nos ofrece además la oportunidad de conocer a los estudios de fotografía y, sobretodo, de constatar cambios sociales como si estuviésemos ante un archivo.

Esta comunicación pretende así, poner en valor la fotografía como objeto de devoción en el sur de Portugal, remitiendo también al contexto español. Tal propósito, nos lleva a colocar cuestiones sobre preservación y conservación de las colecciones de exvotos fotográficos, las cuales, como se explicará, son estrechamente dependientes de su valorización patrimonial. Partiendo entonces de la observación formal de estos objetos, somos llevados a tratar el pasaje de la pintura hacia la fotografía y, consecuentemente, a estudiar cómo se organizan y conservan las fotografías en las iglesias.

\section{Valorización patrimonial de los exvotos fotográficos}

Como se refiere en la introducción, el impulso principal de esta investigación surge de la necesidad de preservación de las colecciones de exvotos fotográficos. Una vez que estas son poco conocidas, no se les ha dado el valor patrimonial que merecen, quedando en riesgo las acciones de conservación que podrían ser efectuadas. La creación de conocimiento y la sensibilización para la importancia de los exvotos fotográficos, llevará a su valorización, y, como consecuencia, se podrá entonces iniciar un diálogo sobre la conservación de las colecciones de fotografía votiva. Surgirán así otras cuestiones sobre el porqué de conservar y

\footnotetext{
${ }^{2}$ BEIRÃO, C.M., Depósito votivo da II Idade do Ferro de Garvão. Notícia da primeira campanha de escavações, p. 84.
} 
Exvotos fotográficos: la imagen usada como objeto de culto en la región de Alentejo - Photographic votive offerings: the image used as an object of worship in Alentejo region

el cómo conservar las fotografías que se encuentran en estas circunstancias. Cuando se observan las fotografías expuestas en las iglesias se entiende el nivel de deterioración de las mismas y la necesidad de crear un plan de carácter preventivo que permita una desaceleración del avance de las deterioraciones. Cabe destacar que, en Portugal, a pesar de los varios estudios sobre exvotos, la fotografía votiva ha sido dejada de parte en el ámbito académico. No obstante, en España, se encuentran artículos que reflecten sobre esta realidad. De remarcar el texto "Exvotos y Fotografía" de la profesora María de los Santos García Felguera ${ }^{3}$ y, "Nuevos lenguajes, viejas creencias: Fotografía y exvotos" de la profesora Elena Sainz Magaña ${ }^{4}$. A pesar de ello, en los textos encontrados, no hay real consciencia de las cuestiones de conservación y como ellas son determinantes para profundizar el conocimiento sobre esta manifestación religiosa.

En la línea de esta reflexión, se hace necesario comprender la evolución formal de los objetos de culto. Antes de abordar la fotografía, se debe mirar hacia tras y observar la realidad de otros formatos votivos. A pesar de que no se sepa cómo o cuando comenzó la práctica de las ofertas votivas, sabemos que, posiblemente, las ofertas de objetos del cotidiano como símbolo de un acontecimiento y representaciones escultóricas, son de los más antiguos encontrados por arqueólogos. Eurico Gama refiere que el exvoto "é tão velho como o Homem", y que "a Fé, a primeira das três virtudes teologais, esteve sempre associada ao Homem de todas as civilizações, que nos momentos cruciantes da sua vida se voltava para o Além, fosse primeiro apenas pelo pensamento, depois pela oração"6. Centrémonos en la escultura, en la cual cabe destacar el uso de la piedra y del metal, como las placas de plata y oro encontradas en el deposito votivo de Garvão, ejemplo ya referido en este texto. Las piezas escultóricas fueron usadas como representaciones de partes del cuerpo humano, práctica que continua vigente en la actualidad a través de la oferta de moldes en cera y que constituye una de la tipologías de objeto votivo más populares. Estas suelen estar

\footnotetext{
${ }^{3}$ María de los Santos García Felguera (Universidad Pompeu Fabra en Barcelona y Universidad Complutense de Madrid) escribió el artículo "Exvotos y Fotografía" integrado en el libro México y España. Un océano de Exvotos: gracias concedidas, gracias recibidas, publicado por el Museo Etnográfico de Castilla y León, 2008.

${ }^{4}$ Elena Sainz Magaña (Universidad de Castilla-La Mancha) escribió el artículo "Nuevos lenguajes, viejas creencias: Fotografía y exvotos" integrado en el libro Fotografia y Memoria publicado por el Centro de Estudios de Castilla-La Mancha, 2006.

${ }^{5}$ GAMA, E. - Os Ex-votos da Igreja do Senhor Jesus da Piedade de Elvas, p. 7. Traducción: "es tan viejo como el Hombre"

${ }^{6}$ GAMA, E. - Os Ex-votos da Igreja do Senhor Jesus da Piedade de Elvas, p. 7. Traducción: "la Fé, la primera de las tres virtudes teologales, ha estado siempre asociada al Hombre de todas las civilizaciones, que en los momentos cruciales de su vida se giraba hacia el más allá, fuese primero solamente por el pensamiento, después por la oración.”
} 
acompañadas de una cinta y de un pequeño texto en el cual se describe la causa del agradecimiento. Las placas en relieve de metal también han perdurado, a pesar de que tienen menor popularidad. Sin embargo, tal vez lo más inquietante de este formato, sea el hecho de que hoy se puede encuentrar exactamente el mismo tipo de dibujo de ojos. En la capilla de Nossa Senhora do Carmo en la localidad de Azaruja, Évora (fig.1), hay una pequeña colección de placas de metal que estéticamente se aproximan a las placas que se hacían en Garvão, en el siglo IV a.C. (fig.2).

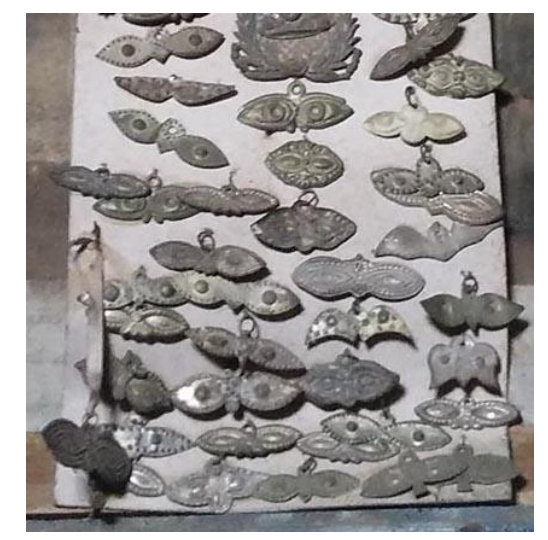

Fig.1 Placas oculares en metal. Ermida de Nossa Senhora do Carmo, Azaruja. Fotografia hecha por la autora.

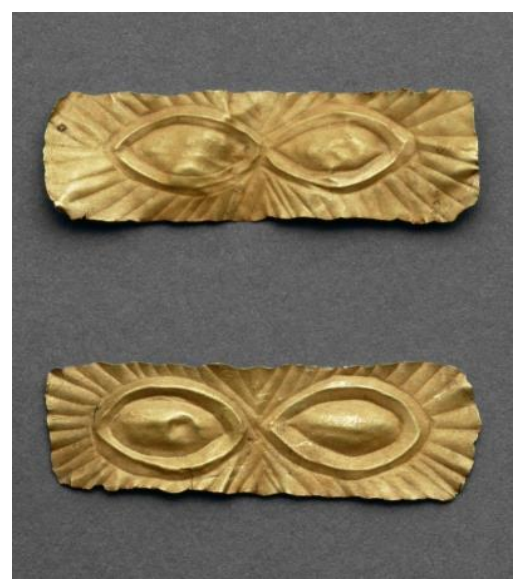

Fig. 2 Placas oculares en oro. Deposito votivo de Garvão. Fotografía de José Pessoa/Direcção-Geral do Património Cultural/Arquivo de Documentação Fotográfica (DGPC/ADF).

Por su parte, la pintura pasó a representar no el cuerpo, sino la situación de enfermedad. La composición pictórica más recurrente, hecha sobre un retablo de madera o placa de metal, muestra la persona enferma acostada en el lecho de una cama rodeada por sus familiares, con la aparición de un santo o santa en la parte superior de la composición, mientras que en la parte inferior suele haber un texto dónde se describe el nombre, la situación, el local y la fecha de los hechos. Esta composición se repite en casi todas las pinturas. La distinción de 
Exvotos fotográficos: la imagen usada como objeto de culto en la región de Alentejo - Photographic votive offerings: the image used as an object of worship in Alentejo region

cada una, reside fundamentalmente en el texto que individualiza la persona y lo ocurrido. En muchos casos, el mismo pintor hace numerosas pinturas para los habitantes de una determinada localidad, lo que conduce a que en su mayoría, tales obras obedezcan a un mismo patrón, tanto a nivel compositivo como en la utilización de determinados colores o elementos decorativos (fig.3-4).

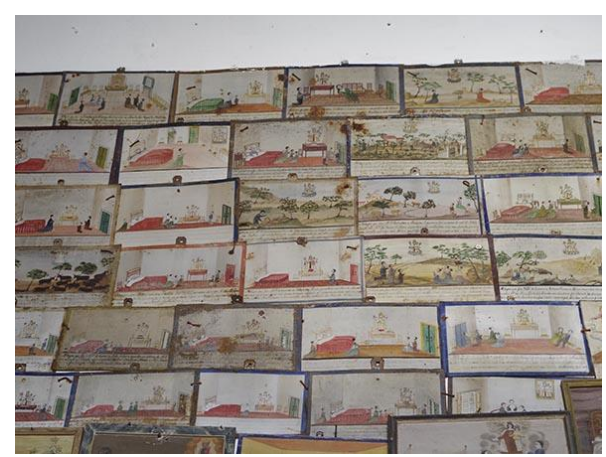

Fig.3 Pinturas sobre metal. Ermida de Nossa Senhora do Carmo, Azaruja. Se destaca la repetición de la composición. Fotografia hecha por la autora.

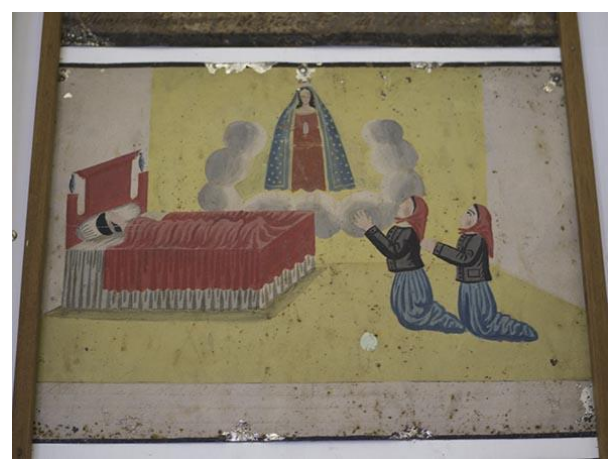

Fig. 4 Pintura sobre metal. Santuário de Nossa Senhora d'Aires, Viana do Alentejo. Fotografia hecha por la autora.

La pintura es el medio que más nos interesa para hablar de la fotografía, una vez que los fotógrafos han seguido lo que ya estaba establecido por los exvotos pictóricos. En los primeros años de utilización de la fotografía como exvoto, es común encontrar las composiciones antes descritas para la pintura. A pesar de no ser llevado a cabo de un modo tan sistemático como en la pintura, la construcción de una situación escenificada fue utilizada por los fotógrafos que han intentado mantener la estética heredada de los retablos. Sin embargo, en el propio ámbito de la fotografía se puede referir las corrientes como el Pictorialismo $^{7}$, o la menos conocida fotografía Academicista $^{8}$, que han puesto en valor

\footnotetext{
${ }^{7}$ Paloma Castellanos, en su libro Diccionario histórico de la fotografía (1999), refiere: "El pictorialismo renovó la cuestión de la relación entre la pintura y la fotografía, una relación de competencia que hizo que la fotografía se elevara al nivel de la pintura, reclamando el mismo prestigio que ésta."
} 
cuestiones estéticas asociadas a la pintura por su composición, temática, o por el tratamiento de la mancha en la imagen. Teniendo en cuenta que estas dos corrientes coinciden en el tiempo, podrán haber tenido influencia en los fotógrafos de estudio que recurrieron al uso de fotomontajes. Pero sobretodo, es innegable la influencia directa de la pintura votiva que antecede a la fotografía y que, en el siglo XIX pasa a ser su contemporánea. Como podemos ver en las (fig.5-6), la decisión del fotógrafo de dónde colocar cada elemento de la escena, se basa enteramente en la composición heredada. Sin embargo, con el paso del tiempo, esta conexión dejó de existir y la fotografía acabó por afirmar su propia estética. Las fotografías pasaron a ser enteramente retratos sin manipulaciones en la cámara oscura. Lo que si permaneció fue el texto, que típicamente sería escrito en un papel e introducido en la parte inferior del marco. A pesar de que la persona retratada fuese reconocida por la imagen, para quien la ofrecía, no bastaría esa obviedad, y sería necesaria la palabra. La palabra escrita, como si de un testamento se tratase, haría que la oferta estuviese completa.

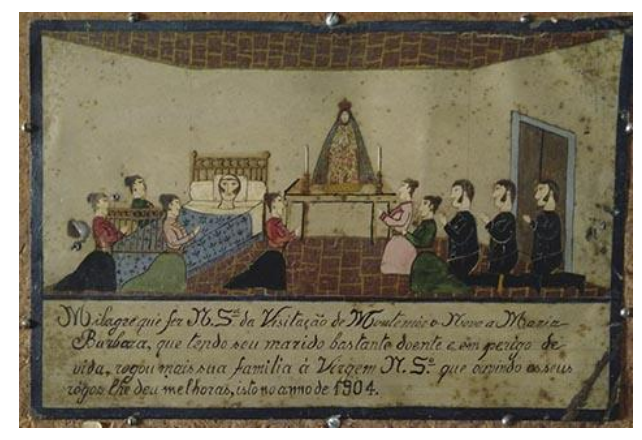

Fig. 5 Pintura sobre metal, 1904. Ermida de Nossa Senhora da Visitação, Montemor-o-Novo. Fotografia hecha por la autora.

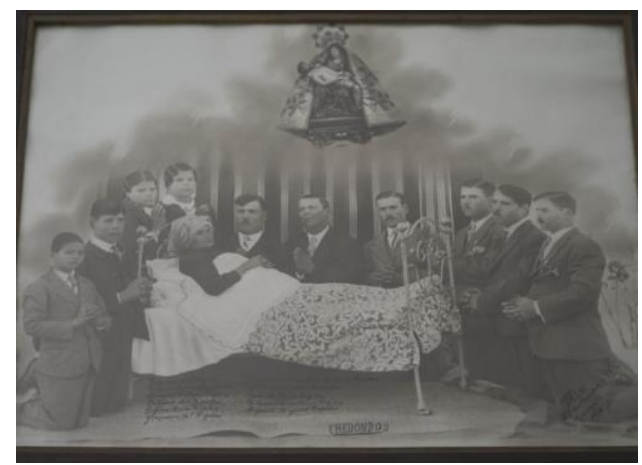

Fig. 6 Retrato de grupo. Santuário de Nossa Senhora d'Aires, Viana do Alentejo. Fotografia hecha por la autora.

\footnotetext{
${ }^{8}$ La fotografía academicista se ha desarrollado en la segunda mitad del siglo XIX y ha ensayado introducir a su practica elementos propios de la pintura. Su surgimiento ha colocado en debate el estatus de fotografía como arte, antecediendo el discurso del pictorialismo.
} 
Exvotos fotográficos: la imagen usada como objeto de culto en la región de Alentejo - Photographic votive offerings: the image used as an object of worship in Alentejo region

Actualmente conviven varios formatos votivos en las iglesias, como la escultura en cera, los objetos como vestidos de novia o botas y, la fotografía. Una gran parte de los espacios dedicados a las ofrendas esta ocupado por retratos, que durante el siglo XX han alcanzado gran popularidad (fig.7-8). Fue sobretodo durante la guerra en las colónias africanas (19611974), que duró hasta la Revolución de 25 de abril, cuando hubo un aumento significativo de exvotos fotográficos. En la mayoría de los casos, estas fotografías representaban el agradecimiento por el regreso de un familiar, pero existen casos en que las fotografías eran entregadas antes de la partida para la guerra pidiendo protección a un santo o santa de su devoción. No obstante, en los días de hoy, a pesar de que continúen ocupando una gran parte de las salas, las ofertas se han reducido sustancialmente. Ya no solo en lo que se refiere a la fotografía, sino también a otros formatos. En el caso de la pintura, su oferta ha desaparecido. Aún así, las iglesias o capillas están repletas de fotografías que deberán ser cuidadas y estudiadas como colecciones, conviviendo con la pintura o la escultura. El universo votivo carece de reconocimiento, en particular en lo que se refiere a la fotografía. A pesar de ello, la dimensión histórica y técnica de esta realidad, que demanda una mirada atenta sobre su valor patrimonial, puede poner en valor las comunidades representadas por las fotografías y, como consecuencia, proporcionar mayor interés por parte de las entidades responsables.

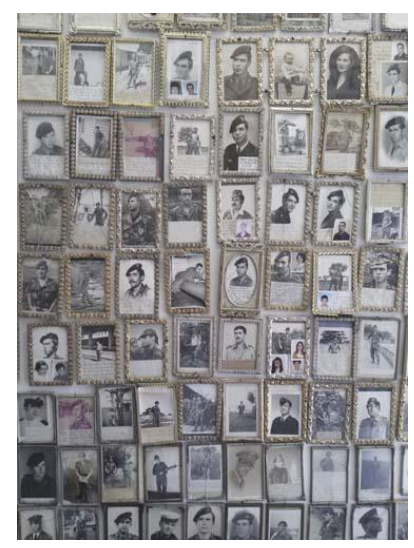

Fig.7 Retrato expuestos en en el Santuário de Nossa Senhora d'Aires, Viana do Alentejo Fotografia hecha por la autora. 


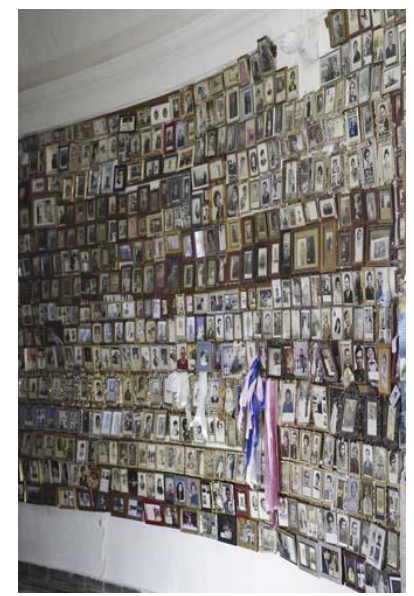

Fig. 8 Retrato expuestos en el Santuário de Nossa Senhora d'Aires, Viana do Alentejo. Fotografia hecha por la autora.

\section{Evolución de la fotografía cómo objeto de devoción}

En 1839, la invención de la fotografía fue divulgada dando protagonismo a Louis Daguerre y al daguerrotipo. A pesar de contar con su nombre, el daguerrotipo fue desarrollado en colaboración con el también pionero de la fotografía Nicéphore Nièpce, que falleció antes del perfeccionamiento de esta técnica. Hubo otros autores igualmente importantes para la invención y consolidación de procesos fotográficos ${ }^{9}$, como, por ejemplo, Henry Fox Talbot, John Hershel, Blanquart-Évrard o Frederic Scott Archer, que contribuyeron para las transformaciones tecnológicas que hicieron de la segunda mitad del siglo XIX un período estimulante tanto a nivel de cámaras como de procesos fotográficos. La aceptación de la fotografía por parte de un público especializado, como científicos o académicos, ocurrió de forma inmediata una vez que pasó a existir la posibilidad de reproducir mecánicamente personas, acontecimientos y todo el tipo de formas naturales o artificiales. A pesar de la curiosidad que se generalizó, el interés por parte del gran publico fue un poco más lento, con la excepción de la alta sociedad. No obstante, entre 1850 y 1860 , la práctica y el conocimiento de la fotografía se consolida, en parte gracias al aparecimiento de los negativos en colodión húmedo, de las copias en albumina y del formato carte de visite ${ }^{10}$ usado para el

\footnotetext{
${ }^{9}$ Proceso fotográfico es el término que se utiliza para denominar las técnicas físico-químicas, a través de las cuales se materializa la imagen fotográfica. En este texto se ha decidido utilizar el vocablo proceso siguiendo el ejemplo del conservador-restaurador y autor de importantes textos en el area, Ángel Ma Fuentes Cía. Sin embargo, la utilización del vocablo procedimiento sería igualmente correcta. Éste, es usado también por el autor antes citado, por el archivero Joan Boadas o por los historiadores de la fotografía Carmelo Vega, Marie-Loup Sougez o Helena Pérez Gallardo.

${ }^{10}$ Carte de Visite es un formato de presentación de una fotografía en papel que se encuentra pegada sobre un soporte de cartón y con una dimensión de 69x110mm. Se ha usado sobretodo para retrato y fue patentada en 1854 por el fotógrafo Brest
} 
Exvotos fotográficos: la imagen usada como objeto de culto en la región de Alentejo - Photographic votive offerings: the image used as an object of worship in Alentejo region

retrato. Podemos afirmar que se normaliza la idea de tener y ofrecer un retrato. Las primeras décadas de circulación y difusión de la fotografía fueron de una riqueza extraordinaria debido a la diversidad de procesos fotográficos y a su perfeccionamiento técnico. De este modo, los avances tecnológicos llevaron a la democratización de la fotografía y, en el viraje del siglo XIX al siglo XX, las clases medias pasarían a ser determinantes para su consumo y mercado. John Tagg refiere, en su libro El peso de la representación, "La historia de la fotografía es ante todo la historia de una industria que satisface esa demanda (demanda social): una historia de necesidades alternativamente fabricadas y satisfechas por un flujo ilimitado de mercancías; un modelo de crecimiento capitalista en el siglo XIX. En ningún otro aspecto es esto tan evidente como en el ascenso del retrato fotográfico que corresponde a una etapa concreta de la evolución social: el ascenso de las clases medias y medias bajas hacia una mayor importancia social, económica y política."11

Como referido anteriormente, durante los primeros años de utilización de la fotografía como exvoto, los fotógrafos recorrían a composiciones semejantes a las usadas en los retablos pictóricos. Para tal, se procedía a un montaje fotográfico realizado en el laboratorio, siendo añadida la imagen de un santo a la composición final. Esta tipología de fotografía, que implicaba la representación del enfermo siendo agraciado, fue fácilmente sustituida por el retrato de estudio, ya fuera este de grupo o individual, de cuerpo entero o primer plano. Observando las colecciones, podemos afirmar que el retrato fue la forma de representación que determinó el uso de la fotografía como exvoto. No existiendo otro medio capaz de reproducir la identidad de forma tan exacta, la fotografía se afirmó, sobreponiéndose a otros medios de representación. Se dejó así de dar valor al escenario de los acontecimientos, pasando a valorizar la identidad del agraciado.

La datación de las fotografías expuestas en las capillas puede ser determinada a través de varias metodologías. Una posibilidad es el estudio de material que nos puede dar una fecha bastante aproximada. Otra, que define balizas temporales más amplias, es la identificación de procesos fotográficos, así como la interpretación de la información que aparece en la imagen. En el caso de los exvotos, una parte de las fotografías ha sido datada por los propios devotos,

Disdéri. Su innovación consistió en producir varias imágenes, del formato antes referido, sobre una misma placa de colodión húmedo, usando un chasis especial y una cámara con varios objetivos.

${ }^{11}$ TAGG, J. - El peso de la representación. Ensayos sobre fotografias y historias, p. 54-55. 
que registraron el año de la oferta ayudando a situar las piezas en el tiempo y lugar. Hasta el momento, a partir de la observación in situ, podemos afirmar que posiblemente la fotografía más antigua se encuentra en Elvas, en el Santuário do Senhor Jesus da Piedade, y se trata de una prueba en papel albuminado de 1874. Sin embargo, será necesario realizar un inventario de los ejemplares existentes en las diversas capillas para así determinar el inicio de la oferta votiva en formato fotográfico en estas colecciones.

Los papeles albuminados fueron presentados por Louis-Désiré Blanquart Evrard a la Academia de las Ciéncias, en Francia, en 1850. Este nuevo soporte fotográfico tuvo muy buena aceptación por parte de los fotógrafos, una vez que se conseguían imágenes con mejor definición que con su antecesor, el papel salado. Los papeles albuminados eran usados para obtener imágenes por contacto directo, que se exponían al sol, y las matrices usadas eran negativos en colodión húmedo sobre soporte de vidrio. Este fue un proceso fotográfico presentado por Frederick Scott Archer en 1851, y tuvo vigencia hasta cerca de 1885. Fue usado en gran escala gracias a sus numerosas ventajas, como posibilitar la realización de copias de altísima calidad, la reducción de los tiempos de exposición y la diminución de los gastos de fabricación. Tales características terminaron por eliminar el daguerrotipo, su antecesor, de la práctica fotográfica. De este modo, como ocurre casi siempre en la historia de la fotografía, la evolución tecnológica llevó a una masificación del uso de la imagen y, en cierta medida, a una democratización de la misma. Como tal, será aceptable pensar que siendo este el primer proceso fotográfico sobre papel usado a gran escala, las fotografías en albumina se podrán encontrar en las colecciones de exvotos y representarán los primeros especímenes fotográficos usados como oferta.

Más allá de las albuminas, en los acervos de las iglesias en estudio, encontramos otros procesos fotográficos como ennegrecimiento directo de gelatina y plata, copias en papel revelación, copias en papel cromógeno y, más recientemente, copias en inyección de tinta. Podemos afirmar que visitar estos locales es como hacer un recorrido por la historia de la fotografía, no solo por sus técnicas, sino también por la presentación de las mismas, es decir, por el tipo de marcos y formatos utilizados. Las capillas de exvotos recuerdan a la función de un álbum, pero en este caso se trata de un álbum representativo de una comunidad, expuesto en las paredes de un lugar considerado sagrado. Cuando lo visitamos, nos es colocada de inmediato la pregunta: cómo era usada la fotografía? Como se fotografiaban las personas, 
Exvotos fotográficos: la imagen usada como objeto de culto en la región de Alentejo - Photographic votive offerings: the image used as an object of worship in Alentejo region

como se vestía el retratado, si la fotografía era hecha en el estudio o en casa, qué fondos eran usados en el estudio y cómo se montaban las fotografías en los marcos. Todas estas cuestiones encuentran respuesta en las capillas de exvotos, siendo determinantes en el reconocimiento de su valor patrimonial.

\section{Problemáticas sobre la conservación de exvotos fotográficos}

La conservación de colecciones fotográficas exige la mayor de las atenciones en lo que respecta a sus condiciones de exposición y a su almacenamiento. Como en cualquier otra área de la conservación y restauración, estos puntos son determinantes para preservar las colecciones, pero lo son todavía más para las de fotografía. Los especímenes fotográficos, independientemente del proceso en el que están realizados, presentan una fragilidad considerable a las alteraciones de humedad relativa, exposición lumínica y contacto con materiales ácidos. En una primera fase de contacto con las colecciones es posible observar deterioraciones consecuentes de estos problemas. Teniendo en cuenta que, en su gran mayoría, las pruebas fotográficas presentan deterioraciones resultantes de los factores antes referidos, es por lo tanto pertinente referenciar parte de ellas en este texto. Es de destacar que debido a la falta de control ambiental, que normalmente se traduce en humedad relativa elevada, surjan problemas como el amarilleamiento de las imágenes y de los soportes, así como presencia de manchas y deformaciones. Por su parte, la humedad elevada provoca la aparición de problemas de biodeterioración como insectos xilófagos que provocan lagunas en la imagen, manchas, hongos o foxing en el soporte de papel, que consequentemente llevan a la pérdida de imagen (fig.9). Por otra parte, se presentan los problemas derivados de la iluminación, una vez que en muchos casos las fotografías son iluminadas con luz natural. Cabe mencionar el desvanecimiento de la imagen, alteración del color original y oxidación de los soportes en papel. Por último, se debe también destacar el mal almacenamiento y manipulación de estos objetos. Muchos de los marcos se encuentran rotos y con vidrios partidos, provocando la posibilidad de copias rasgadas o con pliegues (fig.10). 


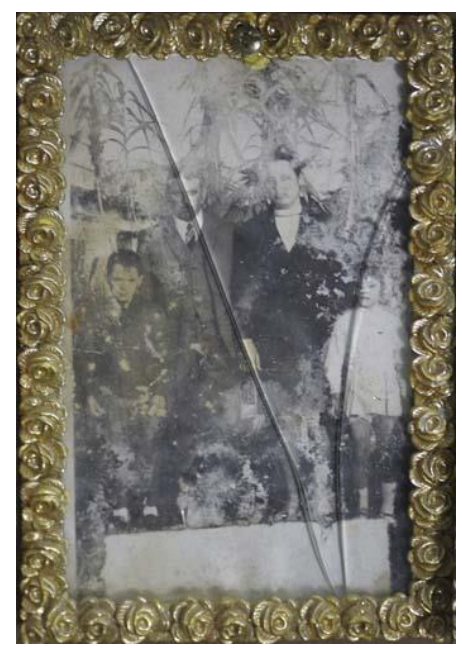

Fig.9 Fotografia y marco deteriorado. Vidrio partido, descomposición de la gelatina y presencia de hongos. Santuário de Nossa Senhora d'Aires, Viana do Alentejo. Fotografia hecha por la autora.

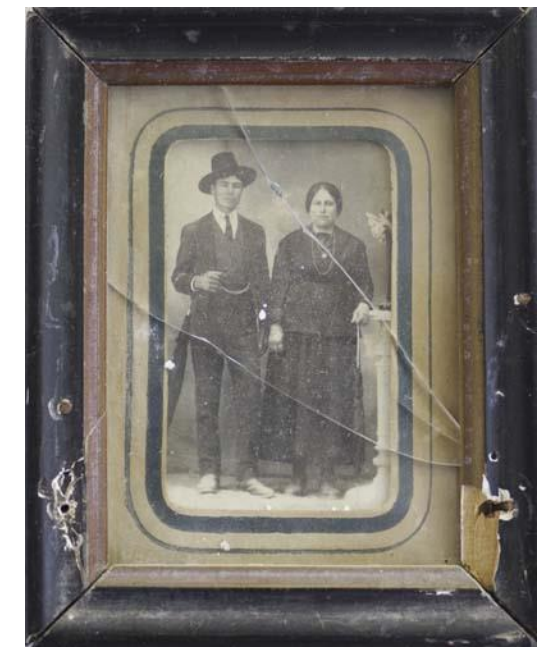

Fig.10 Marco deteriorado. Vidrio partido. Santuário de Nossa Senhora d'Aires, Viana do Alentejo. Fotografia hecha por la autora.

La gran mayoría de las fotografías se encuentra enmarcada, siendo su forma rectangular determinante para la definición de una cuadrícula que ocupa las paredes y, en algunos casos, también los techos de las salas. La gran cantidad de exvotos domina todo el espacio disponible en las iglesias, obligando a aprovechar la totalidad del mismo. Son usados clavos para sujetar los marcos a la pared y, en algunos casos, existe entre los dos un panel de $m d f$ que ayuda a su colocación. Se constata la existencia de una organización por temáticas, como los retratos de militares de la guerra colonial o, a veces, de fotografías de niños (fig.7). Dichas disposiciones han sido configuradas a lo largo de los años por los responsables de las iglesias, que han sido confrontados con las limitaciones de espacio de que disponían. Otra solución encontrada ha sido la utilización de álbumes para fotografías más recientes, muchas de formato carnet y sin moldura. La organización se define así, por la optimización del 
Exvotos fotográficos: la imagen usada como objeto de culto en la región de Alentejo - Photographic votive offerings: the image used as an object of worship in Alentejo region

espacio, por el montaje en marcos y, en algunos casos, por la temática de las fotografías (fig.11).

Es por lo tanto necesario tener en cuenta esta realidad sobre la exposición y organización de los exvotos, así como también, la falta de espacio en las iglesias. Todos los factores aquí referidos intervienen en la preservación de un legado muy específico y valioso para sus comunidades, reforzando la pertinencia de su conservación.

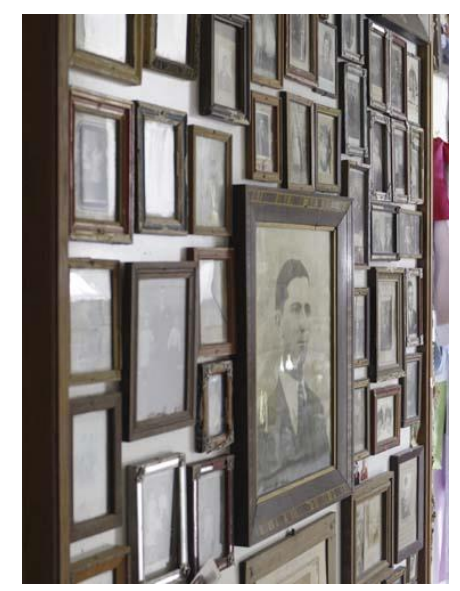

Fig. 11 Fotografias organizadas según el tipo de marco. Santuário de Nossa Senhora d'Aires, Viana do Alentejo. Fotografia hecha por la autora.

\section{Conclusiones}

Las iglesias son lugares de reunión y de devoción, siendo, por lo tanto, representativas de la cultura de una sociedad. En su interior, las colecciones de exvotos fotográficos son la prueba física de devoción, pero no nos enseñan solamente el culto a un símbolo religioso. Cuando las observamos entendemos la evolución de una sociedad y como esta se relacionaba con la fotografía. Más allá de las cuestiones sociales, las colecciones son representativas de la historia de la fotografía, una vez que en ellas podemos encontrar testimonios físicos de la evolución de los procesos fotográficos y de sus materiales, y, sobretodo una de las vías de entendimiento de la historia de la fotografía y de los fotógrafos locales.

La intención de este artículo consiste en alertar para un universo fotográfico y religioso poco estudiado hasta los días de hoy. A través del mismo, se ha hecho evidente el valor patrimonial de las colecciones fotográficas expuestas en iglesias y la necesidad de preservarlas. Si no existe un plan de valorización y de conservación que proteja las fotografías y su forma de exposición, este patrimonio estará condenado al desaparecimiento, una vez que la fotografía impresa es cada vez más residual. Las ofertas votivas en soporte fotográfico difícilmente 
continuarán existiendo debido al pasaje del soporte analógico al digital. Por lo tanto, este formato de exvotos esta condenado a la discontinuidad y los que llegaron a los días de hoy desaparecerán si no hay un plan de actuación que vise su conservación y registro de la información que contienen. Un trabajo que involucre las diferentes dimensiones desarrolladas a lo largo de este texto, desencadenará por sus características de estudio histórico y fin preventivo, acciones que permiten la valorización y divulgación patrimonial no solo de las fotografías votivas, sino también de las iglesias o pueblos dónde estas colecciones se encuentran.

\section{Referencias bibliográficas}

ALMEIDA, C. S., FERNANDES, C. M. (2015). O lápis mágico. Uma história da construção da fotografia. Lisboa: IST Press.

APPELBAUM, B. (1991). Guide to Environmental Protection of Collections. Madison, Connecticut: Sound View Press.

C. M. BEIRÃO, C. T. da SILVA, J. SOARES, M. V. GOMES, R. V. GOMES (1985), "Depósito votivo da II Idade do Ferro de Garvão. Notícia da primeira campanha de escavações", O Arqueólogo Português, série IV, 3, pp. 45-135. Lisboa: Museu Nacional de Arqueologia e Etnologia

BENJAMIN, W. (2005). Sobre la fotografia. Valencia: Ed. Pre-textos.

BERGER, J. (2006). Sobre las propiedades del retrato fotográfico. Barcelona: Editorial Gustavo Gili.

BOADAS, J., CASELLAS, L., SUQUEST, M. À. (2011). Manual para la gestión de fondos y colecciones fotográficas. Girona: GG Ediciones.

BOYLAN, P. J. (2004). Como gerir um museu: manual prático. Paris: ICOM - Conselho Internacional de Museus.

CARDOSO, C. L. (1983) Ex-voto, painéis votivos do rio, do mar e do além-mar. Lisboa: Museu da Marinha.

CARTIER-BRESSON, A. (2008). Le vocabulaire technique de la photographie. Paris: Marval Paris Musée.

DIDI-HUBERMAN, G. (2016) Ex-voto: imagen, órgano, tiempo. Barcelona: Sans Soleil Ediciones.

FUENTES DE CÍA, Á. M. (2012). La conservación de archivos fotográficos. Documentos de trabajo, Sedic - Associación Espanhola de Documentación e Información.

GARCIA FELGUERA, M.S. (2008). "Exvotos y fotografías" en México y España. Un océano de exvotos: gracias concebidas y gracias recibidas. Castilla y León: Museu Etnográfico de Castilla y León. 
Exvotos fotográficos: la imagen usada como objeto de culto en la región de Alentejo - Photographic votive offerings: the image used as an object of worship in Alentejo region

GAMA, E. (1972). Os exvotos do senhor Jesus da Piedade de Elvas. vol. 1, Braga.

LAPA, A. (1967). Livro de exvotos portugueses. Lisboa.

LAVEDRINE, Bertrand (2013). (Re)Connaître et conserver les photographies anciennes. Paris: Éditions du Comité des travaux historiques et scientifiques, Collections orientations et méthodes $\mathrm{n}^{\mathrm{o}} 10$.

LAVEDRINE, B., GANDOLFO, JP., MONOD, S. (2000). Les Collections Photographiques, Guide de Conservation Preventive. Paris: ARSAG.

MEDEIROS, M. (2000). Fotografia e narcisismo. O auto-retrato contemporâneo. Lisboa: Editora Assírio \& Alvim.

NUÑEZ-HERRADOR, E. A., GARCÍA ALCÁZAR, S., MUÑOZ SÁNCHEZ, E. (2006). Fotografia y memoria. I Encuentro en Castilla-La Mancha, Colección almud fotografia 03. Ciudad Real: Centro de estudios de Castilla-La Mancha.

OLIVEIRA, J. F. R. (2009). Das tabulae votivae em Rocha Peixoto aos exvotos do Santuário do Senhor Jesus da Piedade de Elvas. Póvoa do Varzim.

PAVÃO, L. (2001). Conservación de Colecciones de Fotografía. Cuadernos Técnicos. Granada: Editora Junta de Andalucia.

REILLY, JAMES M. (1980). Albumen and Salted Paper Book, The history and practice of photographic printing 1840-1895. Rochester NY: Light Impressions Ed..

SAINZ MAGAÑA, E.. "La presencia por la imagen. Retratos en algunos santuarios de la Mancha". Universidad de Castilla-la Mancha.

TAGG, J. (2005). El peso de la representación. Ensayos sobre fotografias e historias. Barcelona: Editorial Gustvo Gili, SA. 